\title{
Illusory own body perceptions: Case reports and relevance for bodily self-consciousness is $^{3}$
}

\author{
Lukas Heydrich $^{\mathrm{a}, \mathrm{b}}$, Sebastian Dieguez ${ }^{\mathrm{a}}$, Thomas Grunwald ${ }^{\mathrm{c}}$, Margitta Seeck ${ }^{\mathrm{b}}$, Olaf Blanke ${ }^{\mathrm{a}, \mathrm{b}, *}$ \\ ${ }^{a}$ Laboratory of Cognitive Neuroscience, Brain Mind Institute, Ecole Polytechnique Fédérale de Lausanne (EPFL), Switzerland \\ ${ }^{\mathrm{b}}$ Department of Neurology, University Hospital Geneva, Switzerland \\ ${ }^{\mathrm{c}}$ Swiss Epilepsy Center, Zurich, Switzerland
}

\section{A R T I C L E I N F O}

\section{Keywords:}

Epilepsy

Self

Body representation

Depersonalization

Multisensory

Parietal cortex

Medial prefrontal cortex

\begin{abstract}
A B S T R A C T
Neurological disorders of body representation have for a long time suggested the importance of multisensory processing of bodily signals for self-consciousness. One such group of disorders - illusory own body perceptions affecting the entire body - has been proposed to be especially relevant in this respect, based on neurological data as well as philosophical considerations. This has recently been tested experimentally in healthy subjects showing that integration of multisensory bodily signals from the entire body with respect to the three aspects: self-location, first-person perspective, and self-location, is crucial for bodily self-consciousness. Here we present clinical and neuroanatomical data of two neurological patients with paroxysmal disorders of full body representation in whom only one of these aspects, self-identification, was abnormal. We distinguish such disorders of global body representation from related but distinct disorders and discuss their relevance for the neurobiology of bodily self-consciousness.
\end{abstract}

(c) 2010 Elsevier Inc. All rights reserved.

"I am what I seem to be, yet do not seem to be what I am; even to myself I am an insoluble riddle, for my personality has been torn apart!"1

E.T.A. Hoffmann, “The Devil's Elixirs”

\section{Introduction}

Unraveling the neural basis of self-consciousness is a major research topic in the cognitive neurosciences and science at large. One line of research has focused on the contributions of bodily processing and body representation to selfconsciousness (Blanke \& Metzinger, 2009; Craig, 2002; Damasio, 1999; Jeannerod, 2007). Behavioral work in healthy subjects has studied multisensory (Botvinick \& Cohen, 1998; Ehrsson, 2007) and sensorimotor (Blakemore \& Frith, 2003; Blakemore, Frith, \& Wolpert, 1999; Fourneret \& Jeannerod, 1998) aspects of self-consciousness by revealing some of the mechanisms of how bodily processing influences self-consciousness. Neuroimaging studies in healthy subjects have

\footnotetext{
This article is part of a special issue of this journal on Self, Other and Memory.

* Corresponding author. Address: Laboratory of Cognitive Neuroscience, Brain Mind Institute, Ecole Polytechnique Fédérale de Lausanne (EPFL), Swiss Federal Institute of Technology, Station 19, 1015 Lausanne, Switzerland. Fax: +41 (0) 216939625.

E-mail address: olaf.blanke@epfl.ch (O. Blanke).

1 "Ich bin das, was ich scheine, und scheine das nicht, was ich bin, mir selbst ein unerklärlich Rätsel, bin ich entzweit mit meinem Ich!!". E.T.A. Hoffmann, "Die Elixiere des Teufels"
} 
complemented this work on multisensory and sensorimotor mechanisms by measuring some of the associated neural mechanisms - including interoceptive and cognitive aspects of self-consciousness temporo-parietal junction, insula precuneus, and medial prefrontal cortex (for reviews see Blakemore \& Frith, 2003; Craig, 2002; Northoff et al., 2006; Vogeley \& Fink, 2003).

Historically, however, it was the detailed clinical reports of neurological and psychiatric patients suffering from disorders of body representation, and illusory own body perceptions (Critchley, 1953; Hécaen \& Ajuriaguerra, 1952; Ionasescu, 1960; Lhermitte, 1939; Sierra, Lopera, Lambert, Phillips, \& David, 2002), which have suggested close links between bodily processing and self-consciousness for a long time. This clinical work highlighted the importance of multisensory bodily processing in patients suffering from migraine (Lippman, 1952; Podoll \& Robinson, 1999; Todd, 1955), vascular stroke (Critchley, 1953), tumors (Hécaen \& Ajuriaguerra, 1952; Sierra et al., 2002), epilepsy (Blanke, Landis, Spinelli, \& Seeck, 2004; Blanke, Ortigue, Coeytaux, Martory, \& Landis, 2003), and psychiatric disorders (Lukianowicz, 1963).

Such disorders of body representation ${ }^{2}$ have been classified as a variety of alterations in perceptual bodily experience such as the experiences of the absence of a body part (Critchley, 1953; Frederiks, 1969; Hécaen \& Ajuriaguerra, 1952), body part transformations (Critchley, 1953; Hécaen \& Ajuriaguerra, 1952; Ionasescu, 1960; Lippman, 1952), body part displacement (Lippman, 1952; Nightingale, 1982), disconnection of one body part from the body (Blanke et al., 2003; Lippman, 1952), the delusional misidentification of one's own body part (i.e. somatoparaphrenia) (Gerstmann, 1942; Vallar \& Ronchi, 2009), as well as phantom limbs (Hécaen \& Ajuriaguerra, 1952; Lhermitte, 1939), and supernumerary phantom limbs (Khateb et al., 2009; Vuilleumier, Reverdin \& Landis, 1997) (for reviews see (Blanke, Arzy, \& Landis, 2008; Brugger, 2006; Dieguez, Staub, \& Bogousslavsky, 2007; Frederiks, 1969; Hécaen \& Ajuriaguerra, 1952; Menninger-Lerchenthal, 1935). The brain damage leading to these disorders of body representation suggested a predominant involvement of the right posterior parietal cortex and ipsilesional subcortical regions, although other areas were also found to be implicated, i.e. the lateral prefrontal and premotor cortex (Arzy, Overney, Landis, \& Blanke, 2006; Berti et al., 2005; Critchley, 1953; Dieguez et al., 2007; Hécaen \& Ajuriaguerra, 1952) and the right posterior insular cortex (Baier \& Karnath, 2008).

Extending earlier accounts (Brugger, 2002, 2006; Devinsky, Feldmann, Burrowes, \& Bromfield, 1989; Grüsser \& Landis, 1991; Hécaen \& Ajuriaguerra, 1952; Menninger-Lerchenthal, 1935; Mizumoto \& Ishikawa, 2005), we have recently proposed that a well-defined group of disorders of body representation - illusory own body perceptions affecting the entire body (or primarily the head and trunk region) - are especially relevant for the study of bodily self-consciousness (Blanke, 2004; Blanke \& Metzinger, 2009). We highlighted this importance by opposing such illusory own body perceptions with those affecting an isolated extremity or body part and have based this on neurological and neurophysiological data as well as philosophical arguments. Based on clinical data, several research groups have recently developed methods to study the mechanisms of full-body processing and its relationship to self-consciousness experimentally in healthy subjects (Altschuler \& Ramachandran, 2007; Ehrsson, 2007; Lenggenhager, Tadi, Metzinger, \& Blanke, 2007; Mizumoto \& Ishikawa, 2005). These experimental and clinical data jointly suggest that the integration of visual and multisensory bodily signals from the entire body is important for three major aspects of bodily self-consciousness: self-location (SL; the volume in space where humans experience the self to be located ["where I experience to be"]), first-person perspective (1PP; the directedness of conscious experience ["where I experience to perceive the world from"]) and self-identification (SI; the degree to which humans identify with their body ["what I experience as my body"]). SL, 1PP, and SI are abnormal in patients with global illusory own body perceptions (Blanke \& Metzinger, 2009).

Here we present clinical and anatomical data from two epileptic patients suffering from rare illusory own body perceptions associated with abnormal SI and involving predominantly the trunk and head, due to damage to right posterior dorso-medial parietal cortex (patient 1) and the right dorso-medial prefrontal cortex (patient 2). We discuss the phenomenology, etiology, and lesion location in these two cases in regard to the neurological literature and the larger field of the cognitive neuroscience of bodily self-consciousness.

\section{Methods}

Both patients were recruited at the University Hospital of Geneva, where they underwent full diagnostic workup, including a standardized neurological, psychiatric and neuropsychological examination (Pegna, Qayoom, Gericke, Landis, \& Seeck, 1998), electroencephalography (EEG, including source imaging of interictal epileptic spikes, Grave de Peralta Menendez, Gonzalez Andino, Lantz, Michel, \& Landis, 2001; Lantz, Grave de Peralta Menendez, Gonzalez Andino, \& Michel, 2001; Michel et al., 2004), magnetic resonance imaging (MRI) and positron emission tomography (PET). Patient 2 in addition underwent invasive presurgical evaluations at the Swiss Epilepsy Center in Zurich. Epilepsy surgery of patient 2 was performed at the Department of Neurosurgery at the University Hospital of Zurich.

In both patients we conducted a semi-structured interview focusing on aspects of bodily self-consciousness, such as $1 \mathrm{PP}$, SL, SI, as well as somatosensory, visual, auditory, and vestibular symptoms and emotions (following Blanke \& Mohr, 2005). Additionally patient 2 was asked to complete the Cambridge Depersonalization Scale (CDS) (Sierra \& Berrios, 2000). The CDS comprises 29-items inquiring about subjective experiences classically associated with the depersonalization syndrome.

\footnotetext{
${ }^{2}$ Due to the poor definition of the term body schema (as well as the related term body image) and even more importantly its inconsistent use in the neurological literature, we decided to use the more neutral term body representation (see de Vignemont, 2010).
} 
Each item is rated on two Likert scales that quantify frequency (range 0-4) and duration (range 1-6) (cutoff score for depersonalization disorder is 70 ).

\section{Results}

\subsection{Patient 1}

Patient 1 is a 55 year old, left-handed male patient suffering from epilepsy since the age of 14 years. His simple partial sensorimotor seizures affected his left hand had been well controlled under anti-epileptic medication until the onset of paroxysmal episodes of vertigo 9 years before the current hospitalization. At that time he additionally started to experience the following, highly stereotypical pattern of symptoms: without any prior warning he would first have the impression of an increasing pressure in the entire left hemi-body. This sensation increased progressively in strength leading eventually to the sensation that he was invaded by a stranger in his left hemi-body. At this time he also sensed that the left half of his head, the upper part of his left trunk, his left arm and his left leg were no longer belonging to him (no misattribution), that these parts were disconnected from the rest of his body, and that his body was divided into two parts (Fig. 1A). Sometimes this was followed by the impression that the left arm was moving unintentionally and would disappear behind the patient's back. During these episodes he never experienced any deformation or other changes of his body or the environment. Furthermore, no autoscopic hallucinations, no sensation of floating or disembodiment, no change in visuo-spatial or first-person perspective, no disturbance of language or vision and no loss of contact or consciousness were noted. During these sensations the patient localized the self as within the right side of his body (shown in grey in Fig. 1). He managed to remain calm and was able to continue standing, walking, and even give oral presentations while in front of audiences at work (surrounding persons usually did not notice his seizure manifestations). These simple partial seizures occurred on a daily basis and lasted $\sim 1$ min.

Neurological, psychiatric, and neuropsychological examinations were normal. Surface EEG at the time of hospitalization did not reveal any pathological correlates. MRI showed a hypo-dense lesion in the right posterior intraparietal sulcus predominantly in the medial wall in the T1 weighted sequence (Fig. 2), which was confirmed by fluid-attenuated inverse recovery (FLAIR) and PET compatible with arteriovenous malformation. The diagnosis of epileptic seizures was retained,

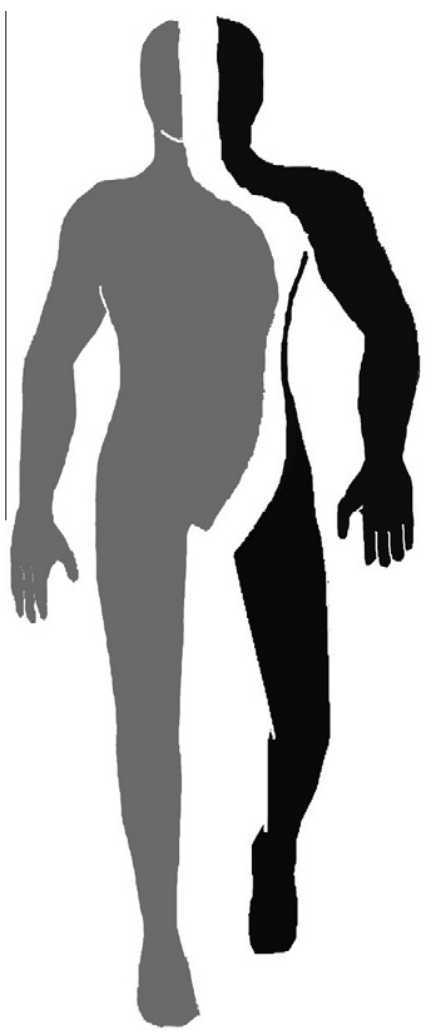

Fig. 1. Phenomenology patient 1 . Simple partial seizures were characterized by the impression of increasing pressure in the entire left hemi-body. This sensation increased progressively in strength leading eventually to the sensation that he was invaded by a stranger in his left hemi-body. At this time he also sensed that the left half of his head, the upper part of his left trunk, his left arm and his left leg were no longer belonging to him, that these parts were disconnected from the rest of his body, and that his body was divided into two parts. 

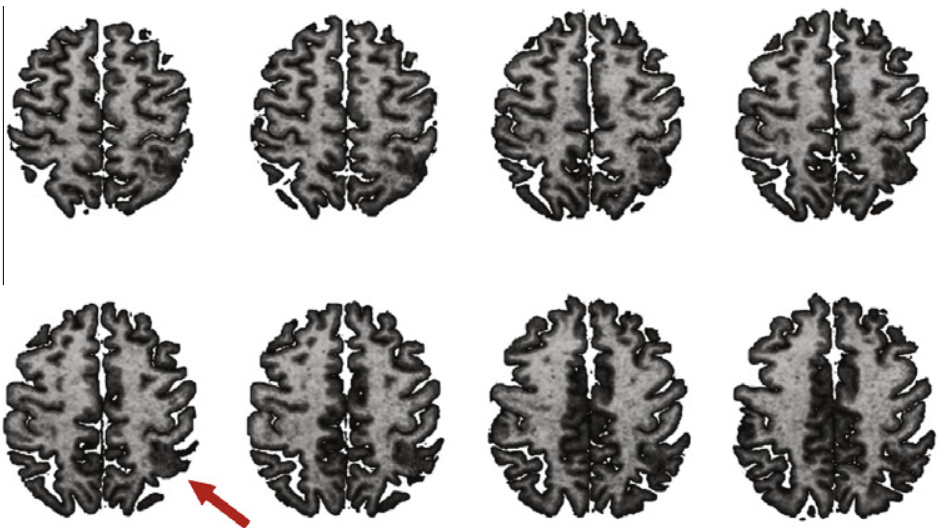

A

Fig. 2. MRI patient 1. T1-weighted magnetic resonance imaging reveals a hypointense cortical and subcortical lesion in the right posterior intraparietal sulcus (arrows), consistent with an arteriovenous malformation. (A) Axial view, (B) 3-D reconstruction. The hypointense lesion is indicated by an arrow.

even though no epileptic discharges were recorded on repeated EEGs. This was based on the history of the patient (left-lateralized seizures as a child), the current symptomatology, and the corresponding neocortical lesion location.

\subsection{Patient 2}

Patient 2 is a 30 year old, left-handed male patient suffering from pharmaco-resistant epilepsy. He was referred to the presurgical epilepsy unit at the University Hospital of Geneva and the Epilepsy Clinic in Zurich for further evaluation.

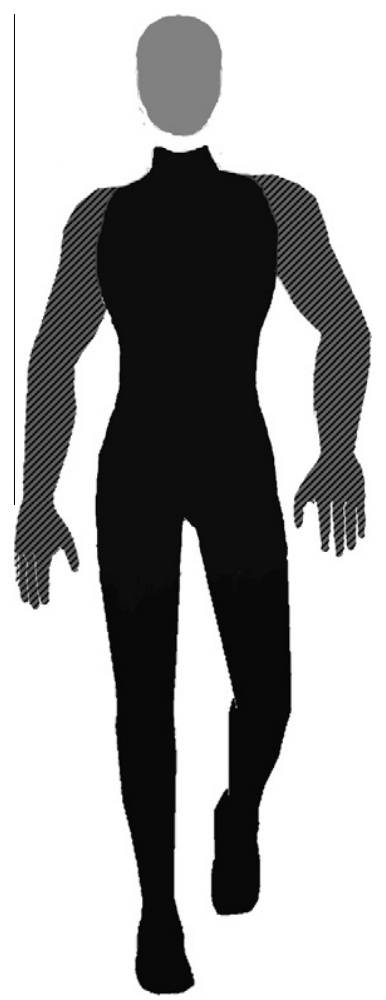

Fig. 3. Phenomenology patient 2. Complex partial seizures were characterized by altered bodily awareness including a total loss or a strongly diminished awareness of bodily signals, which predominated at the lower trunk and legs and also included - to a lesser degree - his upper trunk and neck (black; the patient could not indicate whether the upper extremities were affected or not, illustrated by dashed black and grey lines). This was accompanied by the impression that everything below his neck was "numb", "useless" and somewhat inaccessible to conscious awareness while the experience of his head region was experienced as light and as detached from the rest of his lower body (light grey). 
Seizures started at the age of 11 years, with episodes characterized by the following intense feelings of altered bodily awareness. During these episodes he felt a total loss or a strongly diminished awareness of his body (that he compared to numbness). This sensation was localized and predominated at the legs and lower trunk and also included - to a lesser degree - his upper trunk and neck (the patient could not indicate whether the upper extremities were affected or not (Fig. 3 ). This altered bodily awareness progressively increased in strength and eventually led to the impression that everything below his neck was "numb", "useless" and somewhat inaccessible to conscious awareness whereas the perception of his head remained unaffected and was even experienced as light and as detached from the rest of his lower body. Following this, he described that he felt "as an observer of his body and as the one being observed" at the same time. However, he never experienced floating, elevation, or vestibular sensations, nor a change in visuo-spatial or first-person perspective, and he never felt physically disembodied (as is typically mentioned in out-of-body experiences; (Blanke et al., 2004; Brugger, Regard, \& Landis, 1997; Devinsky et al., 1989) nor saw an image of himself in external space (autoscopy; i.e. (Blanke et al., 2004; Brugger et al., 1997).

The patient also noted a feeling of disconnection from his own thoughts and past, and that he was no longer in control of his actions and speech, like being a robot. In addition the patient often felt as if being detached from the environment, as if sounds and voices were being transformed and distant, perceived as if "through a veil". These sensations were mostly observed as isolated auras but also could indicate the imminent onset of a complex partial seizure with involuntary movements of the left arm, head deviation to the left, loss of consciousness, and secondary tonic-clonic generalization. The frequency of these auras was variable, ranging from one per day to one per hour and most often occurred during phases of relaxation. The duration was estimated as $\sim 30 \mathrm{~s}$. Different anti-epileptic drugs were tried without any success. Family history and personal history were negative for epilepsy or psychiatric disease.

Neurological and psychiatric examinations were unremarkable. The interictal neuropsychological evaluation showed executive and attentional deficits: high distractibility and intrusive thoughts, as well as mild impairments in mental flexibility. The CDS yielded a score of 46 . Ictal and interictal high resolution EEG recordings ( 128 channels) revealed right frontal and fronto-temporal spikes, spike-waves, and sharp waves and subsequent source imaging of epileptic spikes (Grave de Peralta Menendez et al., 2001; Lantz et al., 2001; Michel et al., 2004) suggested an epileptogenic focus in the right middle and superior frontal gyrus (Fig. 4A). Single photon emission tomography (SPECT) demonstrated a hyper-perfusion of the right middle frontal gyrus, the right anterior cingulate cortex, and the bilateral operculum. Repeated MRI did not show any lesion, but intracranial EEG recordings and functional mapping using 52 surgically implanted subdural grid electrodes revealed an epileptogenic focus in the right supplementary motor area (SMA) and the right superior frontal gyrus (Fig. 4B). Subsequent complete resection of the right SMA and partial resection of the right superior frontal gyrus resulted in partial seizure control. There were no more seizures during the day and significantly fewer seizures during sleep. No more auras have been described since this first operation (15 months follow-up). Meanwhile, this first topectomy has been extended during a second epilepsy surgical procedure, after which no seizures have recurred yet (4 month follow-up).
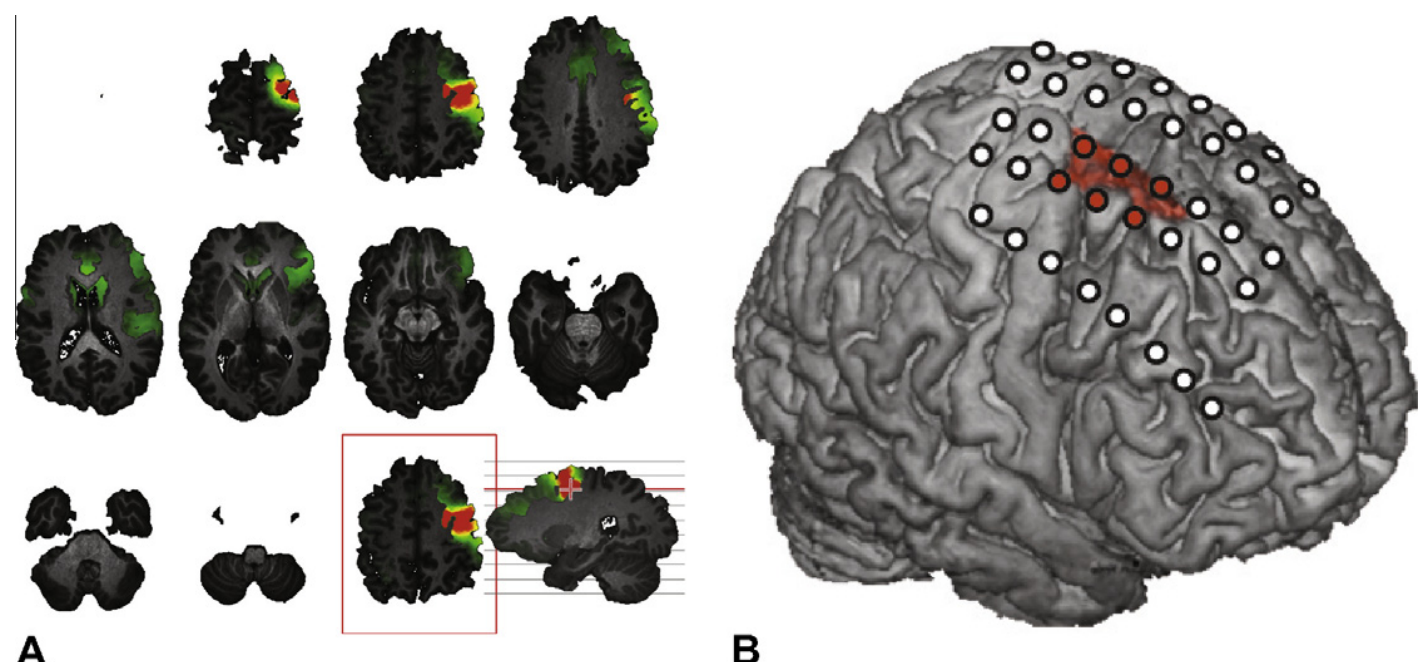

Fig. 4. A. Interictal Spike Mapping. Interictal Spike Mapping with 256-channel EEG in patient 2 and source imaging of epileptic spikes suggested an epileptogenic focus in the right middle and superior frontal gyrus. The significant voxels at a $p<0.01$ threshold (corrected for multiple comparisons, e.g. for the number of electrodes using Bonferroni correction) are indicated in green. The maximum of the estimated source of the averaged interictal spike is indicated in red (Lantz et al., 2001). B. Intracranial EEG and functional mapping. Intracranial EEG recordings and functional mapping using 52 surgically implanted subdural grid electrodes revealed an epileptogenic focus in the right supplementary motor area (SMA) and the right superior frontal gyrus (these electrodes are indicated in red). Subsequent partial resection of the right superior frontal gyrus and the SMA resulted in partial seizure control (postoperative lesion indicated in red). After a second operation extending the topectomy no seizures have recurred yet. (For interpretation of the references to colour in this figure legend, the reader is referred to the web version of this article.) 


\section{Discussion}

We present two patients suffering from non-visual illusory own body perceptions due to epilepsy that affected the head-trunk region of the body and were accompanied by a disturbance of SI with the body. Patient 1 suffered from abnormal own body perceptions restricted to his left contralesional hemi-body including the head that was experienced as strange, as if invaded by a stranger, and as if disconnected from his right ipsilesional hemi-face and -body. Patient 2 reported abnormal own body perceptions for the trunk, neck, and the legs bilaterally (but not the head), which were experienced as weaker and numb and as if disconnected from the head. In both patients these illusory own body perceptions were caused by neocortical epilepsy involving two dorso-medial brain regions that have been linked to self-related processing by recent cognitive neuroscience work in healthy subjects. Here, we (1) distinguish such rare illusory own body perceptions (those that affect the head-trunk region) from the more commonly reported illusory own body perceptions that affect the contralesional upper extremity and discuss their underlying neural correlates, (2) propose that they share aspects with certain cases of somatoparaphrenia and visual illusory own body perceptions, (3) discuss their relevance for the study of bodily self-consciousness, and (4) highlight contributions of the dorso-medial posterior parietal cortex and prefrontal cortex for the neurobiology of bodily self-consciousness.

\subsection{Illusory own body perceptions: head and trunk versus upper extremity}

Compared to most patients with disorders of body representation, the present two patients differ concerning the affected body part, the size of the affected body surface and their underlying neural correlates. Disorders of body representation are usually characterized by an alteration in bodily experience that mostly concerns the contralesional upper extremity and are mostly caused by damage to the right ventro-lateral prefrontal cortex, right inferior parietal cortex, or right temporo-parietal cortex. Classically, these are the experience of the absence of a body part (Arzy et al., 2006; Critchley, 1953; Frederiks, 1969; Hécaen \& Ajuriaguerra, 1952), of body part transformations (Critchley, 1953; Hécaen \& Ajuriaguerra, 1952; Ionasescu, 1960; Lippman, 1952), of body part displacement (Lippman, 1952; Nightingale, 1982), of a disconnection of one body part from the body (Blanke et al., 2003; Lippman, 1952), as well as somatoparaphrenia (Gerstmann, 1942; Vallar \& Ronchi, 2009) and supernumerary phantom limbs (Khateb et al., 2009).

A discussion of the present two patients with respect to somatoparaphrenia seems particularly relevant and we will focus here on this comparison. Somatoparaphrenia is associated with somatosensory and hemiplegic motor deficits of the contralesional (mostly upper) extremity as well as neglect and results mostly from damage to right temporo-parietal cortex and/or the right insula (Baier \& Karnath, 2008). Somatoparaphrenic patients typically misidentify the affected hand as belonging to somebody else or misidentify another person's hand as belonging to themselves (Baier \& Karnath, 2008; Gerstmann, 1942; Vallar \& Ronchi, 2009). This condition is often considered an important condition to study bodily self-consciousness, especially concerning self-attribution of the affected extremity. Yet, Blanke and Metzinger (2009) have argued that the aspects of bodily self-consciousness that are crucial for the conscious self (SL, 1PP, SI) are rather based on global body representations in the brain. Yet, as no change in 1PP, SL (the self is experienced as localized within the patient's body, e.g. head-trunk) and SI (e.g. only the contralesional hand is not attributed to the self, whereas the patients still do self-identify with their body) is noted in somatoparaphrenia. Thus, the study of such patients does not allow to study the conscious self as defined by SL, 1PP, SI.

This differed in both present patients who suffered from abnormal self-identification. Patient 1 experienced a strange and disconnected contralesional hemi-body including trunk, neck, head and extremities and patient 2 experienced a disconnection from his neck, trunk and both lower extremities, that were felt as less present and numb. In addition, patient 1 reported that the perceptually altered body segments were experienced as invaded by (the body of) another person. Especially the latter aspect, but also the involvement of the midline body region (that affected the head in patient 1 ) and the larger extension of the affected body surface, suggests the presence of a disorder of self-identification with the body of the patients at a more global level than somatoparaphrenia.

These observations of abnormal self-identification with one's own head and/or trunk are reminiscent of earlier clinical observations in patients with somatoparaphrenia, in whom not only a limb, but also the contralesional hemi-body was affected (Gerstmann, 1942; Glonning, Jellinger, \& Tschabiter, 1963; Hoff \& Pötzl, 1935/1988; Lhermitte, 1939; MenningerLerchenthal, 1935; Pötzl, 1925, for reviews see Blanke et al., 2008; Brugger, 2006). Thus, Pötzl (1925; case 1) described a patient with left-sided hemiplegia who not only claimed that his left arm belonged to an unknown person, as seen in many patients with somatoparaphrenia, but also that there was another (unseen) person lying in his bed to his left and that this person tried to push him out of the bed. Engerth and Hoff (1929) described a 71 year-old man with left-sided hypoesthesia, hemianopia (with hemianopic hallucinations), and anososognosia who experienced a constant left-sided person who was most often localized next or behind the patient. Biancone described a 72 year-old female patient with left-sided hemiplegia and hemianesthesia that claimed that her left hemi-body belonged to another person that was lying in her bed (quoted after Lhermitte, 1939). In some rare cases, the body of the felt other is even experienced as invading the patient's body, as noted by patient 1 . Thus, a patient with a parasagittal meningioma adjacent to the right posterior parietal cortex reported by Nightingale (1982) described that his left hemi-body felt strange, seemed to have shifted backwards and was invaded (and controlled) by external agents (mostly the patient's father). Another patient reported by Gloning (1963, case 1) also reported that her left hemi-body felt strange compared to her right hemi-body and was shifted backwards, due to a glioma in right posterior occipito-parietal cortex. These reports point to the importance of the right posterior and medial parietal 
cortex for illusory own body perceptions that do not only affect the contralesional hand but also the midline trunk/head region making self-identification and self-other distinction more ambiguous. We also note that perceptual aberrations and abnormal self-identification of these patients and patient 1 are also comparable to some patients suffering from heautoscopy and the feeling of a presence (for review, see Blanke et al., 2008) that may be associated with an experienced split of the trunk and/or head (e.g. Blanke et al., 2008; Brugger, Blanke, Regard, Bradford, \& Landis, 2006). Finally there might also be a partial overlap with the concept of ego-pathology as described by Scharfetter (1981), which has mainly been applied to psychiatric patients.

\subsection{Self-identification and neural full-body representation}

Here, we argue that disturbances in self-identification and perceptual aberrations with respect to the head and/or trunk region are observed when head and/or trunk representations in medio-dorsal parietal or prefrontal cortex are affected. This contrasts functionally and anatomically with damage to more ventro-lateral regions in parietal and prefrontal cortex that are more typically lesioned in patients with perceptual aberrations affecting a certain body part (Arzy et al., 2006; Berti et al., 2005; Hécaen \& Ajuriaguerra, 1952). This dissociation between head and trunk versus arm and hand is compatible with the major functional properties of single neurons in posterior parietal cortex. Neurons in primary somatosensory cortex (for example area $3 \mathrm{~b}$ ) have small tactile receptive fields that respond preferentially or only to stimuli applied to a specific and contralateral body part (such as the finger tip or the toe (Gardner, 1988). Neurons in area 1 and 2 have larger receptive fields and respond to stimuli applied to one hand or foot and neurons in unimodal somatosensory association cortex (area 5; (Taoka, Toda, Iriki, Tanaka, \& Iwamura, 2000) have even larger receptive fields responding to cutaneous stimuli applied to proximal parts of an extremity or the trunk. Yet, neurons with somatosensory receptive fields that encode the hemi-body or the entire body (global somatosensory receptive fields) have also been described in the ventral intraparietal region (VIP). These neurons respond to and encode preferentially the head and trunk region, but may encode also the left or right hemi-body, the upper or lower hemi-body, or the entire body surface (Duhamel, Colby, \& Goldberg, 1991, 1998). These VIP neurons have not only large somatosensory receptive fields, but also large visual receptive fields, and contain many bimodal neurons integrating visual and somatosensory stimuli (Bremmer, Klam, Duhamel, Ben Hamed, \& Graf, 2002; Duhamel et al., 1998; Schlack, Hoffmann, \& Bremmer, 2002). VIP in humans has been suggested to be localized in the intraparietal sulcus (Bremmer et al., 2001) and thus overlaps with the regions affected in patient 1. Cells with similar functional properties are likely to exist in premotor cortex and the SMA (Graziano, 1999; Penfield \& Jasper, 1954). We therefore speculate that processing of VIP in patient 1 and premotor cortex and SMA (and adjacent regions with similar functional properties) in patient 2 was abnormal and gave rise to disturbances in self-identification and perceptual aberrations affecting head and/or trunk and thus full body representations.

\subsection{Cognitive neuroscience of bodily self-consciousness}

The data in patient 2 may further be of relevance for the neurobiology of depersonalization, as he also reported a non-perceptual detachment of the self and loss of self-relevance. Patients suffering from depersonalization often feel detached and alienated from their body and/or mental processes, feeling as an outside "observer", while having no or less control over their actions (DSM-IV., 2000). Although somewhat reminiscent of autoscopic phenomena, such as out-of-body experience or heautoscopy (Brugger, 2002), there is generally no experienced perceptual change in 1PP or in SL in patients with depersonalization. Interestingly, a recent model regarding the neurobiological correlates of depersonalization suggests an involvement of the prefrontal cortex (Sierra \& Berrios, 1998) proposing that increased prefrontal activity may lead to limbic inhibition that results in decreased autonomic output and hypo-emotionality towards the self and the world. Together with neuroimaging data showing the medial prefrontal cortex's role in cognitive aspects of self-related processing (Northoff et al., 2006), its recruitment during behavioral tasks demanding imagined perspective transformations (Vogeley \& Fink, 2003), it may be suggested that activity in the medial prefrontal cortex may reflect more cognitive than spatial aspects of the $1 \mathrm{PP}$, including self reference, self concept and a mental representation of oneself as a subject of experience that may be disturbed in patients with depersonalization.

Although bodily self-consciousness and its three components, SI, 1PP, and SL, have been linked to multisensory integration at the temporo-parietal junction, careful study of patients with depersonalization as well as patients with disorders of body representation affecting the head and/or trunk region may provide additional insights into the neurobiology of selfhood. Such self-related brain activity is likely to be distributed in a network of brain regions including the temporoparietal junction, the dorso-medial parietal cortex, the prefrontal cortex and the default network (Ehrsson, Spence, \& Passingham, 2004; Gusnard, Akbudak, Shulman, \& Raichle, 2001; Hanakawa et al., 2003; Kircher et al., 2000; Macrae, Moran, Heatherton, Banfield, \& Kelley, 2004; Maguire et al., 1998; Northoff et al., 2006; Ruby \& Decety, 2001; Vogeley \& Fink, 2003).

\section{Acknowledgments}

LH and MS are supported by the Swiss National Science Foundation (Grants 33CM30-124089, 33CM30-123115, 320030122073, 323530-123718). OB was supported by the Swiss National Science Foundation (Sinergia Grant CRSII1-125135: Balancing Self and Body). 


\section{References}

Altschuler, E. L., \& Ramachandran, V. S. (2007). A simple method to stand outside oneself. Perception, 36(4), 632-634.

Arzy, S., Overney, L. S., Landis, T., \& Blanke, O. (2006). Neural mechanisms of embodiment: Asomatognosia due to premotor cortex damage. Archieves of Neurology, 63(7), 1022-1025.

Baier, B., \& Karnath, H. O. (2008). Tight link between our sense of limb ownership and self-awareness of actions. Stroke, 39(2), 486-488.

Berti, A., Bottini, G., Gandola, M., Pia, L., Smania, N., Stracciari, A., et al (2005). Shared cortical anatomy for motor awareness and motor control. Science, 309(5733), 488-491.

Blakemore, S. J., \& Frith, C. (2003). Self-awareness and action. Current Opinion in Neurobiology, 13(2), 219-224.

Blakemore, S. J., Frith, C. D., \& Wolpert, D. M. (1999). Spatio-temporal prediction modulates the perception of self-produced stimuli. Journal of Cognitive Neuroscience, 11(5), 551-559.

Blanke, O. (2004). Out of body experiences and their neural basis. BMJ, 329(7480), 1414-1415.

Blanke, O., Arzy, S., \& Landis, T. (2008). Chapter 22 Illusory reduplications of the human body and self. Handbook of Clinical Neurology, 88, 429-458.

Blanke, O., Landis, T., Spinelli, L., \& Seeck, M. (2004). Out-of-body experience and autoscopy of neurological origin. Brain, 127(Pt 2), $243-258$.

Blanke, O., \& Metzinger, T. (2009). Full-body illusions and minimal phenomenal selfhood. Trends in Cognitive Sciences, 13(1), 7-13.

Blanke, O., \& Mohr, C. (2005). Out-of-body experience, heautoscopy, and autoscopic hallucination of neurological origin implications for neurocognitive mechanisms of corporeal awareness and self-consciousness. Brain Research Brain Research Reviews, 50(1), $184-199$.

Blanke, O., Ortigue, S., Coeytaux, A., Martory, M. D., \& Landis, T. (2003). Hearing of a presence. Neurocase, 9(4), 329-339.

Botvinick, M., \& Cohen, J. (1998). Rubber hands 'feel' touch that eyes see. Nature, 391(6669), 756.

Bremmer, F., Klam, F., Duhamel, J. R., Ben Hamed, S., \& Graf, W. (2002). Visual-vestibular interactive responses in the macaque ventral intraparietal area (VIP). European Journal of Neuroscience, 16(8), 1569-1586.

Bremmer, F., Schlack, A., Shah, N. J., Zafiris, O., Kubischik, M., Hoffmann, K., et al (2001). Polymodal motion processing in posterior parietal and premotor cortex: A human fMRI study strongly implies equivalencies between humans and monkeys. Neuron, 29(1), $287-296$.

Brugger, P. (2002). Reflective mirrors: Perspective-taking in autoscopic phenomena. Cognitive Neuropsychiatry, 7(3), $179-194$.

Brugger, P. (2006). From phantom limbs to phantom bodies: Varieties of extracorporeal awareness. In G. Knoblich, I. M. Thornton, M. Grosjean, \& M. Shiffrar (Eds.), Human body perception from the inside out (pp. 171). Oxford: Oxford University Press.

Brugger, P., Blanke, O., Regard, M., Bradford, D. T., \& Landis, T. (2006). Polyopic heautoscopy: Case report and review of the literature. Cortex, 42(5), 666-674.

Brugger, P., Regard, M., \& Landis, T. (1997). Illusory reduplication of own's own body: Phenomenology and classification of autoscopic phenomena. Cognitive Neuropsychiatry(2), 19-38.

Craig, A. D. (2002). How do you feel-now? The anterior insula and human awareness. Nature Reviews Neuroscience, 10(1), 59-70.

Critchley, M. (1953). The parietal lobes. New York, London: Hafner Publishing Company.

Damasio, A. (1999). The feeling of what happens. London: Random House.

de Vignemont, F. (2010). Body schema and body image-pros and cons. Neuropsychologia, 48(3), 669-680.

Devinsky, O., Feldmann, E., Burrowes, K., \& Bromfield, E. (1989). Autoscopic phenomena with seizures. Archieves of Neurology, $46(10), 1080-1088$.

Dieguez, S., Staub, F., \& Bogousslavsky, J. (2007). Asomatognosia. In O. Godefroy \& J. Bogousslavsky (Eds.), The behavioral and cognitive neurology of stroke (pp. 215-253). Cambridge: Cambridge University Press.

DSM-IV (2000). Diagnostic and statistical manual of mental disorders-DSM-IV (4th ed.). Washington, DC: American Psychiatric Association.

Duhamel, J. R., Colby, C. L., \& Goldberg, M. E. (1991). Congruent representations of monkey ventral intra-parietal cortex (area VIP). In J. Paillard (Ed.), Brain and space. Oxford University Press.

Duhamel, J. R., Colby, C. L., \& Goldberg, M. E. (1998). Ventral intraparietal area of the macaque: Congruent visual and somatic response properties. Journal of Neurophysiology, 79(1), 126-136.

Ehrsson, H. H. (2007). The experimental induction of out-of-body experiences. Science, 317(5841), 1048.

Ehrsson, H. H., Spence, C., \& Passingham, R. E. (2004). That's my hand! Activity in premotor cortex reflects feeling of ownership of a limb. Science, 305(5685), 875-877.

Engerth, G., \& Hoff, H. (1929). Ein Fall von Halluzinationen im hemianoptischen Gesichtsfeld. Beitrag zur Genese der optischen Halluzinationen. Monatschr Psychiatr Neurol, 74, 246-256.

Fourneret, P., \& Jeannerod, M. (1998). Limited conscious monitoring of motor performance in normal subjects. Neuropsychologia, 36(11), 1133-1140.

Frederiks, J. A. M. (1969). Disorders of the body schema. In G. W. Bruyn \& P. J. Vinken (Eds.). Handbook of clinical neurology (Vol. 4, pp. 207-240). .

Gardner, E. P. (1988). Somatosensory cortical mechanisms of feature detection in tactile and kinesthetic discrimination. Canadian Journal of Physiology and Pharmacology, 66(4), 439-454.

Gerstmann, J. (1942). Problem of imperception of disease and of impaired body territories with organic lesions. Relation to body schema and its disorders. Archives of Neurology and Psychiatry, 48, 890-913.

Glonning, I., Jellinger, K., \& Tschabiter, H. (1963). Über einen obduzierten Fall von optischer Körperschemastörung und Heautoskopie. Neuropsychologia, 1, $217-231$.

Grave de Peralta Menendez, R., Gonzalez Andino, S., Lantz, G., Michel, C. M., \& Landis, T. (2001). Noninvasive localization of electromagnetic epileptic activity. I. Method descriptions and simulations. Brain Topography, 14(2), 131-137.

Graziano, M. S. (1999). Where is my arm? The relative role of vision and proprioception in the neuronal representation of limb position. Proceedings of the National Academy Sciences of the United States of America, 96(18), 10418-10421.

Grüsser, O.-J., \& Landis, T. (1991). The splitting of 'I' and 'me': Heautoscopy and related phenomena. In T. Grüsser \& O.-J. Landis (Eds.), Visual agnosias and other disturbances of visual perception and cognition (pp. 297-303). Amsterdam: MacMillan.

Gusnard, D. A., Akbudak, E., Shulman, G. L., \& Raichle, M. E. (2001). Medial prefrontal cortex and self-referential mental activity: Relation to a default mode of brain function. Proceeding of the National Academy of Sciences of the United States of America, 98(7), 4259-4264.

Hanakawa, T., Immisch, I., Toma, K., Dimyan, M. A., Van Gelderen, P., \& Hallett, M. (2003). Functional properties of brain areas associated with motor execution and imagery. Journal of Neurophysiology, 89(2), 989-1002.

Hécaen, H., \& Ajuriaguerra, J. (1952). Méconnaissances et hallucinations corporelles. Paris: Masson.

Hoff, H., \& Pötzl, O. (1935/1988). Transformation between body image and external worl. In J. Brown (Ed.), Agnosia and apraxia: Selected papers of liepmann, lange, and pötzl (pp. 251-262). Hillsdale, NJ: Lawrence Erlbaum.

Ionasescu, V. (1960). Paroxysmal disorders of the body image in temporal lobe epilepsy. Acta Psychiatrica Scandinavica, 35, $171-181$.

Jeannerod, M. (2007). Being oneself. Journal of Physiology Paris, 101(4-6), 161-168.

Khateb, A., Simon, S. R., Dieguez, S., Lazeyras, F., Momjian-Mayor, I., Blanke, O., et al (2009). Seeing the phantom: A functional magnetic resonance imaging study of a supernumerary phantom limb. Annals of Neurology, 65(6), 698-705.

Kircher, T. T., Senior, C., Phillips, M. L., Benson, P. J., Bullmore, E. T., Brammer, M., et al (2000). Towards a functional neuroanatomy of self processing: Effects of faces and words. Brain Research Cognitive Brain Research, 10(1-2), 133-144.

Lantz, G., Grave de Peralta Menendez, R., Gonzalez Andino, S., \& Michel, C. M. (2001). Noninvasive localization of electromagnetic epileptic activity. II. Demonstration of sublobar accuracy in patients with simultaneous surface and depth recordings. Brain Topography, 14(2), $139-147$.

Lenggenhager, B., Tadi, T., Metzinger, T., \& Blanke, O. (2007). Video ergo sum: Manipulating bodily self-consciousness. Science, 317(5841), 1096-1099.

Lhermitte, J. (1939). L'image de notre corps (Editions de la Nouvelle Revue Critque ed.). Paris.

Lippman, C. W. (1952). Certain hallucinations peculiar to migraine. Journal of Nervous and Mental Disease, 116(4), 346-351.

Lukianowicz, N. (1963). "Body image" disturbances in psychiatric disorders. British Journal of Psychiatry, 113(494), 31-47. 
Macrae, C. N., Moran, J. M., Heatherton, T. F., Banfield, J. F., \& Kelley, W. M. (2004). Medial prefrontal activity predicts memory for self. Cerebral Cortex, 14(6), $647-654$.

Maguire, E. A., Burgess, N., Donnett, J. G., Frackowiak, R. S., Frith, C. D., \& O’Keefe, J. (1998). Knowing where and getting there: A human navigation network. Science, 280(5365), 921-924.

Menninger-Lerchenthal, E. (1935). Das Truggebilde der eigenen Gestalt. Berlin: S. Karger.

Michel, C. M., Murray, M. M., Lantz, G., Gonzalez, S., Spinelli, L., \& Grave de Peralta, R. (2004). EEG source imaging. Clinical Neurophysiology, 115(10), 2195-2222

Mizumoto, M., \& Ishikawa, M. (2005). Immunity to error through misidentification and the bodily illusion experiment. Journal of Consciousness Studies, 12(7), 3-19.

Nightingale, S. (1982). Somatoparaphrenia: A case report. Cortex, 18(3), 463-467.

Northoff, G., Heinzel, A., de Greck, M., Bermpohl, F., Dobrowolny, H., \& Panksepp, J. (2006). Self-referential processing in our brain - A meta-analysis of imaging studies on the self. Neuroimage, 31(1), 440-457.

Pegna, A. J., Qayoom, Z., Gericke, C. A., Landis, T., \& Seeck, M. (1998). Comprehensive postictal neuropsychology improves focus localization in epilepsy. European Neurology, 40(4), 207-211.

Penfield, W., \& Jasper, H. (1954). Epilepsy and the functional anatomy of the human brain. Boston: Little, Brown and Company.

Podoll, K., \& Robinson, D. (1999). Lewis Carroll's migraine experiences. Lancet, 353(9161), 1366.

Pötzl, O. (1925). Über Störungen der Selbstwahrnehmung bei linksseitiger Hemiplegie. Zeitschrift für die gesamte Neurologie und Psychiatrie, 93, 117-168.

Ruby, P., \& Decety, J. (2001). Effect of subjective perspective taking during simulation of action: A PET investigation of agency. Nature Neuroscience, 4(5), $546-550$.

Scharfetter, C. (1981). Ego-psychopathology: The concept and its empirical evaluation. Psychological Medicine, 11(2), 273-280.

Schlack, A., Hoffmann, K. P., \& Bremmer, F. (2002). Interaction of linear vestibular and visual stimulation in the macaque ventral intraparietal area (VIP). European Journal of Neuroscience, 16(10), 1877-1886.

Sierra, M., \& Berrios, G. E. (1998). Depersonalization: Neurobiological perspectives. Biological Psychiatry, 44(9), 898-908.

Sierra, M., \& Berrios, G. E. (2000). The Cambridge Depersonalization Scale: A new instrument for the measurement of depersonalization. Psychiatry Research, 93(2), 153-164.

Sierra, M., Lopera, F., Lambert, M. V., Phillips, M. L., \& David, A. S. (2002). Separating depersonalisation and derealisation: The relevance of the "lesion method". Journal of Neurology Neurosurgery and Psychiatry, 72(4), 530-532.

Taoka, M., Toda, T., Iriki, A., Tanaka, M., \& Iwamura, Y. (2000). Bilateral receptive field neurons in the hindlimb region of the postcentral somatosensory cortex in awake macaque monkeys. Experimental Brain Research, 134(2), 139-146.

Todd, J. (1955). The syndrome of Alice in Wonderland. Canadian Medical Association Journal, 73(9), $701-704$.

Vallar, G., \& Ronchi, R. (2009). Somatoparaphrenia: A body delusion. A review of the neuropsychological literature. Experimental Brain Research, 192(3), $533-551$.

Vogeley, K., \& Fink, G. R. (2003). Neural correlates of the first-person-perspective. Trends in Cognitive Sciences, 7(1), 38-42.

Vuilleumier, P., Reverdin, A., \& Landis, T. (1997). Four legs. Illusory reduplication of the lower limbs after bilateral parietal lobe damage. Archives of Neurology, 54(12), 1543-1547. 